\title{
Changes of Cardiac Biomarkers after High-intensity Exercise in Male and Female Elite Athletes of Dragon Boating
}

\author{
Pascal Bauer $^{1}$, Sven Zeißler ${ }^{2}$, Rüdiger Walscheid ${ }^{3}$, Frank C. Mooren ${ }^{4}$ and Andree Hillebrecht ${ }^{4,5}$ \\ 1. Department of Cardiology and Angiology, University Hospital Giessen, Giessen 35390, Germany \\ 2. Faculty of Physical Education and Sports, Comenius University Bratislava, Bratislava 800 00-899 00, Slovakia \\ 3. Department of Laboratory Medicine, Koblenz 56068, Germany \\ 4. Faculty of Sports Medicine, Justus-Liebig-University Giessen, Giessen 35394, Germany \\ 5. Gesundheitswesen Volkswagen AG, Baunatal 34225, Germany
}

\begin{abstract}
This study investigated the effects of three sport-specific high-intensity training units on cardiac biomarker alteration in elite athletes of dragon boating. Thirty six male (age $33 \pm 9$ ) and twenty nine female (age $31 \pm 8$ ) elite athletes, members of the German national team, were examined in their final training camp preparing for world championship. At two time points blood panels (pre-training and one hour post-training) were collected and concentrations of high sensitive troponin $\mathrm{T}$, N-terminal pro brain natriuretic peptide (NT-pro BNP), creatine phosphokinase (CPK), MB-creatine kinase (CKMB) and myoglobin were assessed. After exercise, serum levels of NT-pro BNP, CPK, myoglobin and CKMB increased significantly $(P<0.01$ for each) with only few values exceeding the upper reference limits. High sensitive troponin $\mathrm{T}$ remained below the limit of detection both before and after exercise in all athletes. Significant gender-related differences were found with a higher increase of NT-pro BNP levels in female athletes $(P<0.01)$ compared to males. In contrast, male athletes displayed a significant higher increase of CPK $(P<0.01)$ and myoglobin $(P<0.01)$ compared to female athletes. In conclusion, three high-intensity training units did not lead to elevated high sensitive troponin $\mathrm{T}$ concentrations in elite athletes of dragon boating but to significant increases of NT-pro BNP, CPK and myoglobin levels. This suggests that high-intensity training units do not lead to a cardiac injury in these athletes.
\end{abstract}

Key words: Cardiac damage, high sensitive troponin, NT-pro BNP, sports medicine, exercise.

\section{Introduction}

Prolonged strenuous exercise leads to an elevation of cardiac specific biomarkers such as troponin $\mathrm{T}(\mathrm{TnT})$, troponin I (TnI), MB-creatine kinase (CKMB) and $\mathrm{N}$-terminal pro brain natriuretic peptide (NT-pro BNP) in apparently healthy endurance athletes [1-18]. These parameters are assumed to indicate cardiac injury or dysfunction $[5,18]$ since troponin $\mathrm{T}$ and troponin $\mathrm{I}$ are highly specific markers of myocardial cell damage, even in the presence of simultaneous skeletal muscle damage [16]. Furthermore significant cardiac stress leads to an elevation of these biomarkers even in

Corresponding author: Pascal Bauer, M.D., Dr. med., research field: sports cardiology. absence of obstructive coronary disease [1]. Elevated concentrations of NT-pro BNP reflect elevated myocardial wall stress caused by volume or pressure overload [11]. In clinical routine, it is a helpful tool for diagnosis of cardiac dysfunction, acute coronary syndrome (ACS) or chronic heart failure. In an exercise setting, it seems possible that NT-pro BNP displays increased myocardial activity, since an elevation is often seen after different form of exercises [11]. Though temporarily elevated concentrations of these cardiac biomarkers in healthy athletes after strenuous exercise are assumed to be normal findings [7-9, 13, 15, 19], the mechanisms that lead to this phenomenon are not yet been understood. Several studies come to the 
conclusion that this might be a benign finding as a result of a physiological response to exercise $[11,15$, 20], though some studies found a temporary reduction in cardiac function following prolonged endurance exercise [20-22]. Predictors of a higher post-exercise increase of cardiac biomarkers were, based on a review of the literature, especially high exercise intensity and long exercise duration.

Elevations of skeletal muscle markers as myoglobin and creatine phosphokinase (CPK) are regularly found after strenuous exercising in athletes [6,23], indicating exercise-induced skeletal muscle damage [6, 23]. In sports medicine, monitoring of CPK obtains information about the state of the muscle and provides information on the physical status of the athlete and might reveal subclinical muscle disease, as it is known that some athletes display permanent elevated CPK concentrations [23]. For detection of myocardial muscle damage, more cardiac specific biomarkers, including $\mathrm{CKMB}$ and cardiac troponins have been identified $[1,16]$. A CKMB/CK ratio of more than 5\% is likely to be caused by myocardial damage, as the isoenzyme CKMB is found predominantly in heart muscle cells [16].

The aim of this present study was to investigate the effects of high intensity exercise training on specific cardiac biomarkers in both male and female elite dragon boating athletes. There are only limited data in literature for exercise-induced changes of cardiac biomarkers in athletes with a major strain for the upper body since the majority of studies investigated marathon or ultra-marathon runners. Furthermore, female athletes are underrepresented in literature and there exist no data for exercise-induced changes of cardiac biomarkers in female elite athletes of dragon boating.

\section{Methods}

\subsection{Design Overview}

A quasi-experimental design study was implemented with a pre- and post-test measurement to determine the effects of a high-intensity training on specific cardiac biomarkers in both male and female elite athletes of dragon boating. All participants gave their written informed consent and filled in a questionnaire to register health status, medication, supplementation, training and competition history. The study was approved by the local Research Ethics Committee of the University of Giessen.

\subsection{Participants}

In total 65 athletes, 36 men (age $33 \pm 9$ ) and 29 women (age $31 \pm 8$ ) of the German national team were examined during the final training camp in preparation for the world championships in dragon boating.

The examination took place on the first day of the training camp. All athletes completed three high-intensity training units with a total duration of 180 minutes. Boats were manned with either male or female athletes. The first blood sample was taken before the training units in a sitting position. Each unit lasted for one hour.

Unit 1 was: $4 \times 1000$ meters with start and finish sprint (each lasting for 30 seconds). Unit 2 included: 4 $\times$ start, $2 \times 100 \mathrm{~m}$ sprint and $2 \times 200 \mathrm{~m}$ sprint. Finally the third unit consisted of $1 \times 500 \mathrm{~m}$ and $1 \times 350 \mathrm{~m}$ high intensity competitive training. Between training unit 1 and 2 , the recovery phase lasted one hour, between unit 2 and 3, the recovery phase was two hours. The recovery phase was not standardized, water intake was allowed ad libitum between the units. The second blood sample was taken one hour after the units in a sitting positon, precisely seven hours after the first blood sample was taken.

Detailed data of the participants are given in Table 1.

\subsection{Measurements}

Blood samples were taken from an antecubital vein in a sitting position before and one hour after the complete exercise. Blood samples for plasma analyses were collected into $4.5 \mathrm{~mL}$ vacutainer tubes containing lithium heparin. Samples were centrifugated within 30 
Table 1 Anthropometric data of the examined athletes. Values are given in means \pm standard deviation and additionally divided by gender.

\begin{tabular}{llll}
\hline Gender & male $(n=36)$ & female $(n=29)$ & all athletes $(n=65)$ \\
\hline Height $(\mathrm{cm})$ & $183 \pm 6.5$ & $168 \pm 5.1$ & $176 \pm 9.6$ \\
Weight $(\mathrm{kg})$ & $87 \pm 8$ & $65 \pm 8$ & $77 \pm 13$ \\
Age (years) & $33 \pm 8.7$ & $31 \pm 8.3$ & $32 \pm 8.5$ \\
Training per week $(\mathrm{h})$ & $10 \pm 3.6$ & $10 \pm 3.2$ & $10 \pm 3.5$ \\
\hline
\end{tabular}

minutes at $2000 \mathrm{~g}$ for 7 minutes, then stored on ice at $4^{\circ} \mathrm{C}$ until automated analysis was performed within two hours after acquiring the blood samples.

Creatine phosphokinase activity was measured per UV-absorption by using Modular Analytics Swa (Roche Diagnostics Mannheim, Germany). The measuring range is 0.05 to $38.4 \mu \mathrm{kat} / 1$ (=3-2300 U/l). The upper reference limit is $174 \mathrm{U} / \mathrm{l}$ for men and 140 $\mathrm{U} / \mathrm{l}$ for women.

MB-creatine kinase (CKMB) activity was measured per immune inhibition test by Modular Analytics Swa (Roche Diagnostics Mannheim, Germany). The measuring range is 0.05 to $38.4 \mu \mathrm{kat} / 1$ (= 3-2300 U/l). The upper reference limit both for men and women is $24 \mathrm{U} / 1$.

NT-pro BNP represents BNP in an equimolar manner. NT-pro-BNP was measured by Modular Analytics E170 (Roche Diagnostics, Mannheim, Germany) in accordance with electro-chemiluminescence immunoassay (ECLIA). The sensitivity of the test is $5 \mathrm{pg} / \mathrm{ml}(0.6 \mathrm{pmol} / \mathrm{l})$, the measuring range is 5 to $35000 \mathrm{pg} / \mathrm{ml}(=0.6$ to 4130 $\mathrm{pmol} / \mathrm{l})$. The upper reference limit was considered 125 $\mathrm{pg} / \mathrm{ml}$ both for men and women. High-sensitive troponin T (hsTnT) was measured by Elecsys Modular Analytics E170 (Roche Diagnostics, Mannheim, Germany) in accordance with electro-chemiluminescence immunoassay (ECLIA). The limit of blank is $3 \mathrm{ng} / \mathrm{l}(\mathrm{pg} / \mathrm{ml})$, measuring range goes up to $10000 \mathrm{ng} / \mathrm{l}$ (pg/ml). Troponin $\mathrm{T}$ concentrations below the limit of blank were set as 0 . The 99th percentile cutoff point both for men and women is < $0.14 \mathrm{ng} / \mathrm{l}(\mathrm{pg} / \mathrm{ml})$ with a $95 \%$ confidence interval of 12.7-24.9 $\mathrm{ng} / \mathrm{L}$ (pg/mL). Myoglobin was measured by Elecsys Modular Analytics E170
(Roche Diagnostics, Mannheim, Germany). Normal ranges are $19-56 \mathrm{ng} / \mathrm{ml}$ for women and $21-98 \mathrm{ng} / \mathrm{ml}$ for men.

\subsection{Statistical Analysis}

For statistical calculation, the software package Microsoft Office Excel 2010, Win Stat version 2010.1 and SPSS 19.0 were used. Data are expressed as the mean \pm standard deviation unless otherwise stated. Gaussian distribution was tested with the Kolmogorov-Smirnov test. The differences between baseline values and the post-exercise values were established for all biomarkers using the students t-test in normal distributed variables (CPK, CKMB, NT-pro $\mathrm{BNP})$. In variables without a normal distribution (myoglobin), the Wilcoxon test was used. The association between an increase (difference between baseline and post-exercise value) in the cardiac biomarker and other relevant variables (e.g. amount of training per week, baseline concentrations of the cardiac biomarker, age of the athlete) were assessed using bivariate Pearsons product moment correlation.

All analyses were completed on males and females separately as well as with all athletes combined. To detect gender differences in the alteration of cardiac biomarkers, the Mann-Whitney-U-test was used. In the present study, the plasma concentration of the cardiac biomarkers was not corrected for change in plasma volume during the exercise intervention because drinking ad libitum was allowed during the two training pauses and a normal hydration status in all athletes was assumed.

For all statistical tests, the threshold for statistical significance was set at $P \leq 0.05$. 
Table 2 Results of the examined cardiac biomarkers before ("pre") and after ("post") three high-intensity training units in all elite athletes of dragon boating and additionally splitted by gender. Values are given in means and standard deviation. Given $P$ values represent changes compared to the respective values before ("pre") training.

\begin{tabular}{|c|c|c|c|c|c|c|c|c|c|}
\hline & \multicolumn{3}{|c|}{ Male athletes $(n=36)$} & \multicolumn{3}{|c|}{ Female athletes $(n=29)$} & \multicolumn{3}{|c|}{ All athletes $(n=65)$} \\
\hline & pre & post & $P$ value & pre & post & $P$ value & pre & post & $P$ value \\
\hline $\begin{array}{l}\mathrm{hsTnT} \\
{[\mathrm{ng} / \mathrm{mL}]}\end{array}$ & $<0.01$ & $<0.01$ & & $<0.01$ & $<0.01$ & & $<0.01$ & $<0.01$ & \\
\hline $\begin{array}{l}\text { NT pro BNP } \\
{[\mathrm{pg} / \mathrm{mL}]}\end{array}$ & $28.0 \pm 17.3$ & $41.8 \pm 25.1$ & 0.05 & $66.2 \pm 28.1$ & $89.1 \pm 38.5$ & $<0.01$ & $45.1 \pm 32.2$ & $63.2 \pm 32.4$ & $<0.01$ \\
\hline CPK [U/L] & $279.6 \pm 114.8$ & $471.3 \pm 232.3$ & $<0.01$ & $125.8 \pm 52.8$ & $187.3 \pm 94.0$ & 0.28 & $211.0 \pm 93.0$ & $343.0 \pm 157.8$ & $<0.01$ \\
\hline $\begin{array}{l}\text { myoglobin } \\
{[\mathrm{ng} / \mathrm{mL}]}\end{array}$ & $59.5 \pm 29.5$ & $152.1 \pm 92.4$ & $<0.01$ & $22.8 \pm 9.6$ & $59.5 \pm 49.4$ & 0.38 & $43.1 \pm 21.4$ & $110.3 \pm 64.7$ & $<0.01$ \\
\hline
\end{tabular}

\section{Results}

The day of the high-intensity exercise training was sunny with outside temperatures between $15^{\circ} \mathrm{C}$ and $26^{\circ} \mathrm{C}$, with a mean of $22^{\circ} \mathrm{C}$. Wind was $3 \mathrm{~m} / \mathrm{s}$ from no specific direction and relative humidity was $42 \%$. All athletes completed the three training units without any medical problems. Detailed data of the results are given in Table 2.

\subsection{Baseline Levels of the Examined Parameters}

As the training units took part in the final training camp preparing for world championship, baseline concentrations of all examined parameters were evaluated to identify pre-existing pathological conditions.

Baseline concentrations of cardiac troponin $\mathrm{T}$ were below the limit of detection in all participating athletes.

NT-pro BNP was found elevated above the reference limit before the training sessions in 7 athletes $(6$ women and one man). The highest value detected was $164 \mathrm{pg} / \mathrm{mL}$ in a female athlete; the only male athlete with elevated baseline value of NT-pro BNP displayed $128 \mathrm{pg} / \mathrm{mL}$. In general, women displayed significant $(P$ $=0.02)$ higher baseline NT-pro BNP values $(66.2 \pm$ $28.1 \mathrm{pg} / \mathrm{mL})$ compared to male athletes $(28.0 \pm 17.3$ $\mathrm{pg} / \mathrm{mL})$.

CKMB concentrations above the reference limit were found in six athletes ( 4 men, 2 women). The $\mathrm{CKMB} / \mathrm{CPK}$ ratio in all these athletes was above 5\% (range $6 \%$ to $46 \%$ ), which is considered to be the threshold to indicate myocardial damage. The highest
CKMB/CPK ratio was $46 \%$ while displaying a normal CPK level (CKMB 33 U/L out of a CPK level of 72 $\mathrm{U} / \mathrm{L})$.

Concentrations of myoglobin above the upper reference limit were found in two male athletes before the training sessions (427 ng/mL and $297 \mathrm{ng} / \mathrm{mL}$ ). Female athletes displayed lower baseline levels of myoglobin $(22.8 \pm 9.6 \mathrm{ng} / \mathrm{mL})$ compared to male athletes $(59.5 \pm 29.5 \mathrm{ng} / \mathrm{mL})$.

Nearly $42 \%$ of all athletes exceeded the upper reference limit of CPK concentrations, which is explained by the setting of this investigation in a final training camp preparing for world championship and the cumulative effect of previously conducted training sessions. The 27 athletes with elevated CPK concentrations consisted of 22 men and 5 women. The highest CPK level detected was $1235 \mathrm{U} / \mathrm{L}$ in a male athlete. In general male athletes showed significant $(P$ $=0.05$ ) higher baseline CPK levels compared to female athletes.

\subsection{Alteration of the Examined Parameters after} Exercise in All Athletes, not Separated by Gender

Regarding all examined athletes, the post-exercise concentrations of CPK $(211 \pm 182 \mathrm{U} / 1$ to $343 \pm 277$ $\mathrm{U} / \mathrm{L}), \mathrm{CKMB}(18 \pm 6.7 \mathrm{U} / \mathrm{L}$ to $21 \pm 8.5 \mathrm{U} / \mathrm{L})$ and myoglobin $(43 \pm 61.4 \mathrm{ng} / \mathrm{mL}$ to $110 \pm 104.6 \mathrm{ng} / \mathrm{mL})$ increased significantly $(P<0.01$ for each).

After exercise, CPK levels of 47 athletes (73\%) exceeded the upper reference limit; the highest value observed was $1340 \mathrm{U} / \mathrm{L}$ in a male athlete. 
The CKMB concentrations above the reference limit were now found in nine athletes (seven men and two women) with a maximum of $62 \mathrm{U} / \mathrm{L}$. All athletes who exceeded the reference limit at baseline also did so after exercising.

Interestingly, the $\mathrm{CKMB} / \mathrm{CK}$ ratio after the training units was found elevated (> 5\%) in only two athletes (two women) with $26 \%$ and $30 \%$.

The concentrations of NT-pro BNP increased significantly from $46 \pm 42.3 \mathrm{pg} / \mathrm{mL}$ to $63 \pm 52.4 \mathrm{pg} / \mathrm{mL}$. Only the seven athletes (six women, one man) who presented elevated baseline levels did these after exercising.

Troponin $\mathrm{T}$ was below $3 \mathrm{ng} / \mathrm{l}$ after exercise in all athletes.

\subsection{Gender Differences in the Exercise Induced Alteration of the Examined Parameters}

Significant gender differences were found after the training bouts.

Male athletes demonstrated a significant increase $(P<0.01)$ in CPK concentrations $(188 \mathrm{U} / \mathrm{L}$ versus 69 $\mathrm{U} / \mathrm{L}$ in female athletes) while women $\operatorname{did} \operatorname{not}(P=0.29)$. This means that CPK levels after the training bouts increased with $106 \%$ in male athletes and only $69 \%$ in female athletes.

The same gender difference could be seen regarding the alteration of myoglobin levels with a significant increase $(P<0.01)$ of $92 \mathrm{ng} / \mathrm{mL}$ in male athletes versus $37 \mathrm{ng} / \mathrm{mL}$ in female athletes $(P=0.38)$.

In contrast, the increase of NT-pro BNP concentrations was significantly $(P<0.01)$ higher in female athletes $(23 \mathrm{pg} / \mathrm{mL})$ compared to males (13 $\mathrm{pg} / \mathrm{mL})$, but was largely explained by higher baseline values. The post-exercise increase in NT-pro BNP was associated with the baseline value ( $\mathrm{r}=0.64, P=0.02)$.

The exercise induced CKMB alteration was not statistically significant both in men and women $(P=$ 0.41 and $P=0.34$, respectively).

\section{Discussion}

This current study shows the effects of cardiac biomarker response to high-intensity training bouts in elite dragon boating as a type of sport with major load for the upper body performed in a sitting position. We found significant post-exercise increases for NT-pro BNP but few data exceeding the upper reference limit with a small sex difference in NT-pro BNP response to dragon boating. Female elite athletes had a higher increase of NT-pro BNP post-exercise, which was likely related to higher baseline concentrations. In contrast to these elevated markers, troponin $\mathrm{T}$ concentrations were not elevated both before and after the training bouts.

Our examination took place in a training camp preparing elite athletes for world championships. As it is known that a high physical training status in healthy individuals correlates to higher levels of CPK, it is not surprising that the baseline concentrations of $\mathrm{CPK}$ in our study exceeded URL in nearly $42 \%$ of the participants (27 out of 65). The ascertained significant increases of CPK, myoglobin and CKMB serum levels after the training units are as well not unexpected since strenuous exercise bouts can lead to a degradation of skeletal muscles [6]. Healthy untrained male individuals have higher concentrations of CPK and myoglobin at rest, presumably related to a greater muscle mass in men [23]. This gender difference perpetuates after exercise as it did in our study. Even permanently elevated CPK concentrations can be found in elite athletes due to the maintaining exercise bouts and are not considered to be pathological [23].

The results of studies regarding troponin release after exercise bouts in elite athletes or recreational athletes are incoherent $[2,9,12,15,19,24]$, yet the mechanisms that lead to a release of troponin after exercise bouts in healthy individuals remain unclear $[12,13,15,20]$. Former studies examined troponin $\mathrm{T}$ and troponin I release mainly in marathon or 
ultra-marathon runners, endurance cyclists and triathletes. The results predominantly confirmed elevated troponin I and troponin $\mathrm{T}$ concentrations after endurance exercise bouts [6, 9, 13]. In contrast, intermittent exercise bouts like indoor soccer or strength training do not seem to be associated with troponin T or I elevations [2].

Thus, this study is the first to examine exercise-induced alteration of cardiac biomarkers in dragon boating elite athletes after high-intensity exercise bouts. Dragon boating is performed in a sitting position with a major strain to the upper body. Though the training units preparing for the world championships had a total exercise duration of three hours and led to a significant increase of CPK, CKMB and myoglobin concentrations, we could not detect elevated cardiac troponin $\mathrm{T}$ concentrations in our study. Since troponin $\mathrm{T}$ concentrations after exercise rapidly decrease to baseline levels in trained athletes, blood samples eventually have to be taken in shorter intervals $[13,25]$. Regarding the high-intensity exercise bouts and the measurement of high sensitive troponin $\mathrm{T}$ in our study, this possibility appears very unlikely. Thus, the type of exertion (continuous or intermittent) may be one main factor that influences troponin $\mathrm{T}$ release after exercise. As we currently observed no exercise induced elevation of troponin $\mathrm{T}$, our results support the previously established findings after heavy resistance training session [2, 26] and after intermittent high-intensity team sports [2, 21].

Though we noticed no exercise- induced release of troponin T in our study, NT-pro BNP levels increased significantly after exercise. Elevated myocardial wall stress caused by volume or pressure overload is mentioned in several studies as reason for this phenomenon and was consistently found after exercise bouts $[1,3,7,11,20,27]$. An increase of NT-pro BNP after exercise bouts is described for different sports and is likely to be seen as a physiological adaptation to exercise conditions with little or poor clinical relevance $[2,12]$. Usually, NT-pro BNP levels remain below the upper reference limit. Exercise-induced increase of NT-pro BNP is not related to the increase of cardiac Troponin probably due to different release mechanisms [7, 11, 27]. Highly intensive activity and long exercise duration are associated with a higher increase of NT-pro BNP $[8,14]$ meanwhile both endurance and intermittent exercise lead to elevated NT-pro BNP levels [2]. Furthermore, baseline levels of NT-pro BNP determine the increase with exercise [2, 14], which is also reflected in our results. Female elite athletes in our study showed higher baseline NT-pro BNP levels and a significantly higher increase after exercise compared to men. Similar results were found for a type of sport with a major load for the lower body. Female indoor soccer players showed a significant increase of NT-pro BNP levels after intermittent exercise and significant higher NT-pro BNP levels 24 hours later [2]. Irrespective of the statistical significance of the increase in NT-pro $\mathrm{BNP}$, only few athletes exceeded the upper reference limit in our investigation, which is similar to the findings of Carranza-Garcia et al. [2]. To confirm clinical relevance, further research on the exercise-induced increase of NT-pro BNP concentrations both in males and females and in different types of sports with different strains will be necessary.

\section{Conclusion}

A high-intensity exercise did not lead to an increase of high sensitive troponin $\mathrm{T}$ both in male and female elite athletes of dragon boating, indicating missing exercise-induced cardiac damage. In contrast, a significant increase in CPK and myoglobin levels could be found as an expression of exercise-induced skeletal muscle injury.

A significant increase in NT-pro BNP concentrations was found which reflects the elevated myocardial wall stress caused by volume overload in a high-intensity exercise setting. As compared to men, women displayed a higher NT-pro BNP increase due to higher baseline NT-pro BNP values. 


\section{References}

[1] Agewall, S., Giannitsis, E., Jernberg, T., and Katus, H. 2011. "Troponin Elevation in Coronary vs. Non-coronary Disease.” European Heart Journal 32 (4): 404-11.

[2] Carranza-Garcia, L. E., George, K., Serrano-Ostariz, E., Casado-Arroyo, R., Caballero-Navarro, A. L., and Legaz Arrese, A. 2011. "Cardiac Biomarker Response to Intermittent Exercise Bouts." International Journal of Sports Medicine 32 (5): 327-31.

[3] Eijsvogels, T. M., Shave, R., van Dijk, A., Hopman, M. T., and Thijssen, D. H. 2011. "Exercise-Induced Cardiac Troponin Release: Real-life Clinical Confusion." Current Medical Chemistry 18 (23): 3457-61.

[4] Eijsvogels, T. M., Hoogerwerf, M. D., Oudegeest-Sander, M. H., Hopman, M. T., and Thijssen, D. H. 2014. "The Impact of Exercise Intensity on Cardiac Troponin I Release." International Journal of Cardiology 171 (1): 3-4.

[5] Herrmann, M., Scharhag, J., Miclea, M., Urhausen, A., Herrmann, W., and Kindermann, W. 2003. "Post-race Kinetics of Cardiac Troponin $\mathrm{T}$ and I and N-Terminal Pro-brain Natriuretic Peptide in Marathon Runners." Clinical Chemistry 49 (5): 831-4.

[6] Jassal, D. S., Moffat, D., Krahn, J., Ahmadie, R., Fang, T., Eschun, G., and Sharma, S. 2009. "Cardiac Injury Markers in Non-elite Marathon Runners." International Journal of Sports Medicine 30 (2): 75-9.

[7] Kim, Y. J., Kim, C. H., Shin, K. A., Kim, A. C., Lee, Y. H., Goh, C. W., Oh, J. K., Nam, H. S., and Park, Y. 2012. "Cardiac Markers of EIH Athletes in Ultramarathon." International Journal of Sports Medicine 33 (3): 171-6.

[8] Legaz-Arrese, A., George, K., Carranza-García, L. E., Munguía-Izquierdo, D., Moros-García, T., and Serrano-Ostáriz, E. 2011. "The Impact of Exercise Intensity on the Release of Cardiac Biomarkers in Marathon Runners." European Journal of Applied Physiology 111 (12): 2961-7.

[9] Mehta, R., Gaze, D., Mohan, S., Williams, K. L., Sprung, V., George, K., Jeffries, R., Hudson, Z., Perry, M., and Shave, R. 2012. "Post-Exercise Cardiac Troponin Release Is Related to Exercise Training History." International Journal of Sports Medicine 33 (5): 333-7.

[10] Park, C. H., Kim, K. B., Han, J., Ji, J. G., and Kwak, Y. S. 2014. "Cardiac Damage Biomarkers Following a Triathlon in Elite and Non-elite Triathletes." Korean Journal of Physiology and Pharmacology 18 (5): 419-23.

[11] Scharhag, J., George, K., Shave, R., Urhausen, A., and Kindermann, W. 2008. "Exercise-associated Increases in Cardiac Biomarkers." Medicine and Science in Sports and Exercise 40 (8): 1408-15.

[12] Scharhag, J., Herrmann, M., Urhausen, A., Haschke, M., Herrmann, W., and Kindermann, W. 2005. "Independent
Elevations of N-terminal pro-brain Natriuretic Peptide and Cardiac Troponins in Endurance Athletes after Prolonged Strenuous Exercise." American Heart Journal 150 (6): 1128-34.

[13] Scherr, J., Braun, S., Schuster, T., Hartmann, C., Moehlenkamp, S., Wolfarth, B., Pressler, A., and Halle, M. 2011. "72-h Kinetics of High-sensitive Troponin $\mathrm{T}$ and Inflammatory Markers after Marathon." Medicine and Science in Sports and Exercise 43 (10): 1819-27.

[14] Serrano-Ostariz, E., Terreros-Blanco, J. L., Legaz-Arrese, A., George, K., Shave, R., Bocos-Terraz, P., Izquierdo-Alvarez, S., Bancalero, J. L., Echavarri, J. M., Quilez, J., Aragones, M. T., and Carranza-Garcia, L. E. 2011. "The Impact of Exercise Duration and Intensity on the Release of Cardiac Biomarkers." Scandinavian Journal of Medicine \& Science in Sports 21 (2): 244-9.

[15] Shave, R., Baggish, A., George, K., Wood, M., Scharhag, J., Whyte, G., Gaze, D., and Thompson, P. D. 2010. "Exercise-induced Cardiac Troponin Elevation: Evidence, Mechanisms and Implications." Journal of the American College of Cardiology 56 (3): 169-76.

[16] Thygesen, K., Alpert, J. S., and White, H. D. for the Joint ESC/ACCF/AHA/WHF Task Force. 2007. "Universal Definition of Myocardial Infarction." Journal of the American College of Cardiology 50 (22): 2173-95.

[17] Traiperm, N., Gatterer, H., Wille, M., and Burtscher, M. 2012. "Cardiac Troponins in Young Marathon Runners." American Journal of Cardiology 110 (4): 594-8.

[18] Vidotto, C., Tschan, H., Atamaniuk, J., Pokan, R., Bachl, N., and Muller, M. M. 2005. "Responses of N-Terminal Pro-brain Natriuretic Peptide (NT-proBNP) and Cardiac Troponin I (cTnI) to Competitive Endurance Exercise in Recreational Athletes." International Journal of Sports Medicine 26 (8): 645-50.

[19] Fu, F., Nie, J., and Tong, T. K. 2009. "Serum Cardiac Troponin $\mathrm{T}$ in Adolescent Runners: Effects of Exercise Intensity and Duration." International Journal of Sports Medicine 30 (3): 168-72.

[20] Shave, R., and Oxborough, D. 2012. "Exercise-induced Cardiac Injury: Evidence from Novel Imaging Techniques and Highly Sensitive Cardiac Troponin Assays." Progress in Cardiovascular Diseases 54 (5): 407-15.

[21] George, K. P., Dawson, E., Shave, R., Whyte, G., Jones, M., Hare, E., Gaze, D., and Collinson, P. 2004. "Left Ventricular Systolic Function and Diastolic Filling after Intermittent High Intensity Team Sports." British Journal of Sports Medicine 38 (4): 452-6.

[22] Neilan, T. G., Januzzi, J. L., Lee-Lewandrowski, E., Ton-Nu, T. T., Yoerger, D. M., Jassal, D. S., Lewandrowski, K. B., Siegel, A. J., Marshall, J. E., Douglas, P. S., Lawlor, D., Picard, M. H., and Wood, M. J. 2006. "Myocardial Injury and Ventricular Dysfunction 
Related to Training Levels among Nonelite Participants in the Boston Marathon." Circulation 114 (22): 2325-33.

[23] Brancaccio, P., Maffulli, N., and Limongelli, F. M. 2007. "Creatine Kinase Monitoring in Sport Medicine." British Medical Bulletin 81-82 (1): 209-30.

[24] Mingels, A. M., Jacobs, L. H., Kleijnen, V. W., Laufer, E. M., Winkens, B., Hofstra, L., Wodzig, W. K., and van Dieijen-Visser, M. P. 2010. "Cardiac Troponin T Elevations, Using Highly Sensitive Assay, in Recreational Running Depend on Running Distance." Clinical Research in Cardiology: Official Journal of the German Cardiac Society 99 (6): 385-91.

[25] Middleton, N., George, K., Whyte, G., Gaze, D., Collinson,
P., and Shave, R. 2008. "Cardiac Troponin T Release Is Stimulated by Endurance Exercise in Healthy Humans." Journal of the American College of Cardiology 52 (22): 1813-4.

[26] Stephenson, C., McCarthy, J., Vikelis, E., Shave, R., Whyte, G., Gaze, D., and George, K. 2005. "The Effect of Weightlifting upon Left Ventricular Function and Markers of Cardiomyocyte Damage." Ergonomics 48 (11-14): 1585-93.

[27] Wedin, J. O., and Henriksson, A. E. 2015. "Postgame Elevation of Cardiac Markers among Elite Floorball Players." Scandinavian Journal of Medicine \& Science in Sports 25 (4): 495-500. 